\title{
Temporal Asynchrony of Trophic Status Between Mainstream and Tributary Bay Within a Giant Dendritic Reservoir: The Role of Local-Scale Regulators
}

\author{
Yaoyang Xu • Meiling Shao • Xinqin Han • \\ Qinghua Cai
}

Received: 17 August 2010 / Accepted: 16 November 2010/Published online: 4 December 2010

(C) Springer Science+Business Media B.V. 2010

\begin{abstract}
Limnologists have regarded temporal coherence (synchrony) as a powerful tool for identifying the relative importance of local-scale regulators and regional climatic drivers on lake ecosystems. Limnological studies on Asian reservoirs have emphasized that climate and hydrology under the influences of monsoon are dominant factors regulating seasonal patterns of lake trophic status; yet, little is known of synchrony or asynchrony of trophic status in the single reservoir ecosystem. Based on monthly monitoring data of chlorophyll $a$, transparency, nutrients, and nonvolatile suspended solids (NVSS) during 1-year period, the present study evaluated temporal coherence to test whether local-scale regulators disturb the seasonal dynamics of trophic state indices (TSI) in a giant dendritic reservoir, China (Three Gorges Reservoir, TGR). Reservoir-wide coherences for $\mathrm{TSI}_{\mathrm{CHL}}, \mathrm{TSI}_{\mathrm{SD}}$, and $\mathrm{TSI}_{\mathrm{TP}}$ showed dramatic variations over spatial scale, indicating temporal asynchrony of trophic status. Following the concept of TSI differences, algal
\end{abstract}

Y. Xu $\cdot$ M. Shao $\cdot$ X. Han $\cdot$ Q. Cai $(\bowtie)$

State Key Laboratory of Freshwater Ecology and

Biotechnology, Institute of Hydrobiology,

Chinese Academy of Sciences,

Wuhan 430072, People's Republic of China

e-mail: qhcai@ihb.ac.cn

Y. Xu $\cdot$ X. Han

Graduate University of Chinese Academy of Sciences,

Beijing 100049, People's Republic of China productivity in the mainstream of TGR and Xiangxi Bay except the upstream of the bay were always limited by nonalgal turbidity $\left(\mathrm{TSI}_{\mathrm{CHL}}-\mathrm{TSI}_{\mathrm{SD}}<0\right)$ rather than nitrogen and phosphorus $\left(\mathrm{TSI}_{\mathrm{CHL}}-\mathrm{TSI}_{\mathrm{TN}}<0\right.$ and $\mathrm{TSI}_{\mathrm{CHL}}-\mathrm{TSI}_{\mathrm{TP}}<0$ ). The coherence analysis for TSI differences showed that local processes of Xiangxi Bay were the main responsible for local asynchrony of nonalgal turbidity limitation levels. Regression analysis further proved that local temporal asynchrony for $\mathrm{TSI}_{\mathrm{SD}}$ and nonalgal turbidity limitation levels were regulated by local dynamics of NVSS, rather than geographical distance. The implications of the present study are to emphasize that the results of trophic status obtained from a single environment (reservoir mainstream) cannot be extrapolated to other environments (tributary bay) in a way that would allow its use as a sentinel site.

Keywords Temporal coherence - Trophic state indices · Nonalgal turbidity limitation · Three Gorges Reservoir

\section{Introduction}

Eutrophication has proven to be one of the foremost problems in protecting aquatic ecosystems all over the world (Carpenter et al. 1999; Smith 2003; Carpenter 2005; Nyenje et al. 2010). In the middle of the 20th century, eutrophication was recognized as a serious pollution problem for many western European and 
North American lakes and reservoirs, and began to catch some attention from limnologists since that time (Smith et al. 2006). Research work on the eutrophication process was accelerated in the 1960s and 1970s, and major advances in the scientific assessment, understanding, and management of eutrophication have been made since the late 1960s (Schindler 2006). For example, "Carlson-type" trophic state index (TSI) and its twodimensional graphical approaches have been used frequently for the diagnosis of lake trophic status and its limiting factors (Carlson 1977, 1991; Fernández et al. 2009; Lee et al. 2010). To control eutrophication, the need to reduce anthropogenic nutrient inputs to aquatic ecosystems has been widely recognized (Carpenter et al. 1998, 1999; Conley et al. 2009). In addition, the contribution of water residence time to eutrophication has also been emphasized (Dillon and Rigler 1974; An and Park 2003). In spite of many advances, eutrophication is often a combined effect problem, and much attention is still devoted to the underlying mechanisms of eutrophication (Schindler 2006).

Studies of synchrony in trophic state would contribute to improve our understanding of the relative role of local regulators and regional drivers on eutrophication processes. Many ecological processes are spatially autocorrelated (Lichstein et al. 2002; Shurin et al. 2009), so many ecologists have become more interested in temporal coherence of ecosystem property occurring over spatial scales (Satake and Koizumi 2008; Knowlton and Jones 2007; Patoine and Leavitt 2006; Liebhold et al. 2004) since the concept "synchronization" initially proposed by Moran (1953). Magnuson et al. (1990) defined temporal coherence as "the phenomenon of synchronous fluctuations in one or more parameters among different locations within a geographic region". A key question in ecology concerns is what factors affect the fluctuation of ecosystems over time and space (Heisler and Knapp 2008). The simplicity and generality of temporal coherence make it seductive as a tool to quantify the relative importance of intrinsic factors and extrinsic environmental variations in regulating ecological processes (Grenfell et al. 1998; Hudson and Cattadori 1999; Rusak et al. 1999; Liebhold et al. 2004; Hessen and Faafeng 2006; Rusak et al. 2008; Pöyry et al. 2009). For instance, a significant pattern of synchrony might indicate the prevalence of regional, extrinsic drivers (e.g., climate and hydrology) on the dynamics of the limnological variables. Conversely, if a low level of temporal coherence is found, one may infer the predominance of local-scale regulators. Some studies pointed out that lakes can provide an excellent system to understand synchrony of ecological processes, since the shoreline boundaries enable us to distinguish forces acting from within and from outside the system (Kent et al. 2007). However, recent studies argued that levels of temporal coherence may vary within a single reservoir system with diverse aquatic habits, and emphasized that good tests of temporal coherence within a single system would be its ability to understand the controlling factors of ecosystem and design the excellent monitoring programs (Lansac-Tôha et al. 2008; Xu et al. 2009a).

Three Gorges Reservoir (TGR) located in the mainstream of the Yangtze River (China, Fig. 1) is one of the largest man-made lakes in the world (Huang et al. 2006; Xu et al. 2009b). Since the reservoir was filled to $135 \mathrm{~m}$ above sea level in June 2003, eutrophication and its important characteristics referred to algal bloom have became major problem of water environment in most tributary bays of TGR, and received a lot of attention in recent years (Cai and $\mathrm{Hu}$ 2006; Ye et al. 2007; $\mathrm{Xu}$ et al. 2009a, 2010a). Taste and odor problems increased in frequency and severity in tributary bays, especially in their middle-upper part, when red tide and bluegreen algal bloom were formed during spring and during summer, respectively (Wang et al. 2009; Xu et al. 2010b). Furthermore, water treatment and recreational activities were physically impeded by eutrophication-driven algal blooms. The elucidation of the key factors regulating trophic state has important theoretical and practical significance in the development of management strategy for the reservoir and its watershed management (Straškraba and Tundisi 1999; Wetzel 2001; Poor 2010). While Xu et al. (2010b) had already pointed out that the temporal variation of runoff and suspended solids regulated by subtropical monsoon climate was key regional driver on trophic state of the mainstream of TGR, the effects of localscale regulators on the trophic state of the tributary bay should also be noted due to the obvious difference of aquatic habits from the reservoir mainstream. For example, the mainstream of the TGR was still riverine dominance, while most of tributary bays were lacustrine dominance (Zheng et al. 2006; Xu et al. 2009b), according to the calculated residence time, a useful predictor of similarities and differences among aquatic 


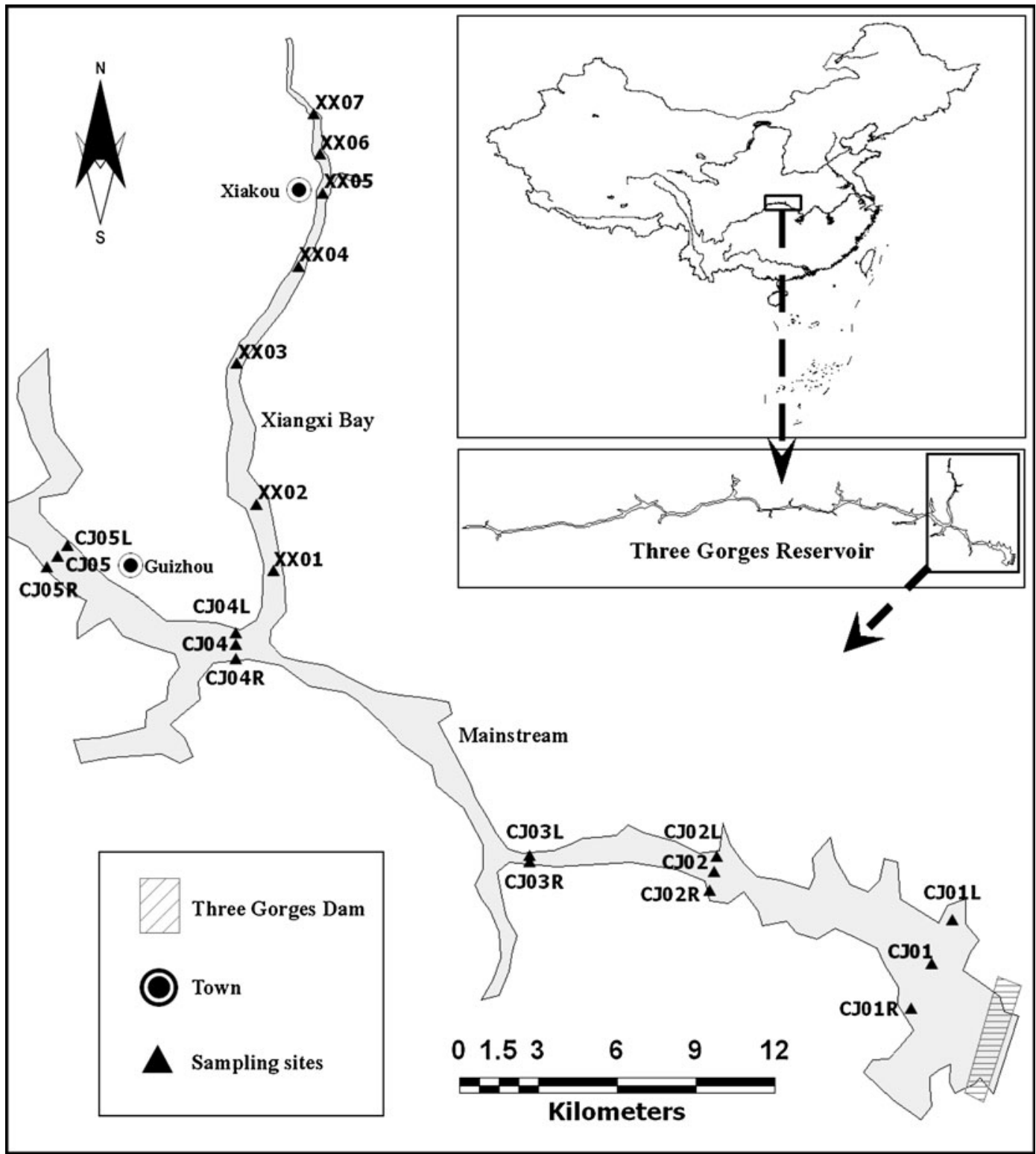

Fig. 1 Location of sampling sites at the mainstream and Xiangxi Bay of TGR

ecosystems (riverine and lacustrine characteristics) (Soballe and Kimmel 1987; Ambrosetti et al. 2003). Moreover, $\mathrm{Xu}$ et al. (2009b) further found that the residence time of the mainstream and Xiangxi Bay of TGR caused a clear variation in nonvolatile suspended solids (NVSS), an important factor regulating trophic state of aquatic ecosystems through the limitations of light availability to algal productivity. Therefore, further research is necessary to test whether local-scale regulators play a key role on temporal asynchrony of trophic state between the mainstream and tributary bay of the reservoir.

Based on monthly data of chlorophyll $a$ (chl. $a$ ), transparency (SD), total nitrogen (TN), total phosphorus (TP), and NVSS between August 2005 and July 2006 from the mainstream and Xiangxi Bay, the present study analyzed temporal coherence for "Carlson-type" trophic state index and their deviations to determine the relative strength of local regulators and regional drivers on eutrophication processes. 


\section{Material and Methods}

\subsection{Design of Sampling}

The TGR was built to reduce the potential for flood, to increase shipping capacity, to produce electricity, and to provide water for irrigated agriculture, domestic, or industrial use. Comprised by the mainstream and around 40 large reservoir-bays, TGR has a capacity of $3.93 \times 10^{10} \mathrm{~m}^{3}$, a water level of $175 \mathrm{~m}$ a.s.l., a surface area of $1,080 \mathrm{~km}^{2}$, and a watershed area of over $1.00 \times$ $10^{6} \mathrm{~km}^{2}$ (Huang et al. 2006). The mainstream and Xiangxi Bay of TGR were selected as the main area for ecological observation and research by the Xiangxi Ecosystem Station, the Chinese Academy of Sciences, and the China Three Gorges Corporation (Fig. 1). Five transverse transects (CJ01-CJ05) were set up along the mainstream of TGR, over a distance of ca. $40 \mathrm{~km}$. CJ01 was just upstream from the dam, and CJ05 was $7 \mathrm{~km}$ upstream from the mouth of Xiangxi Bay. Three sites, located in the left, middle, and right part of the channel, respectively, were set up in each transect, except CJ03 (only two sites) due to the narrow channel. Water depth of sampling site ranged from 21 to $107 \mathrm{~m}$ in the mainstream of TGR (Shao et al. 2008a). Seven sampling sites (XX01-XX07) were set up from the mouth to the headwater of Xiangxi Bay, and their water depth varied between 5 and $70 \mathrm{~m}$ (Shao et al. 2008b). During the survey periods, the sampling sites were recorded using a geographical positioning system (GPS).

\subsection{Field Observation and Samples Measurements}

Twelve surveys were performed monthly from August 2005 to July 2006. Transparency was in situ determined with a $20-\mathrm{cm}$ Secchi disk. Water samples for TN and TP measurements were stored in a 500-ml precleaned plastic bottle, acidified with $\mathrm{H}_{2} \mathrm{SO}_{4}$ to $\mathrm{pH}<2$ and held on ice until laboratory measurement (Huang et al. 2000; Cai 2007). Phytoplankton cells were concentrated by filtering a known volume of water through a microfilter $(0.8 \mu \mathrm{m})$ for chl. $a$ determination (Huang et al. 2000; Cai 2007). An additional known volume of water was filtered through a weighed preignited glass fiber filter (Whatman type GF/F) for suspended solid measurements. All filters were immediately placed in a dark cooler and packed in ice until the laboratory analysis. The chl. $a$ concentrations were determined on a

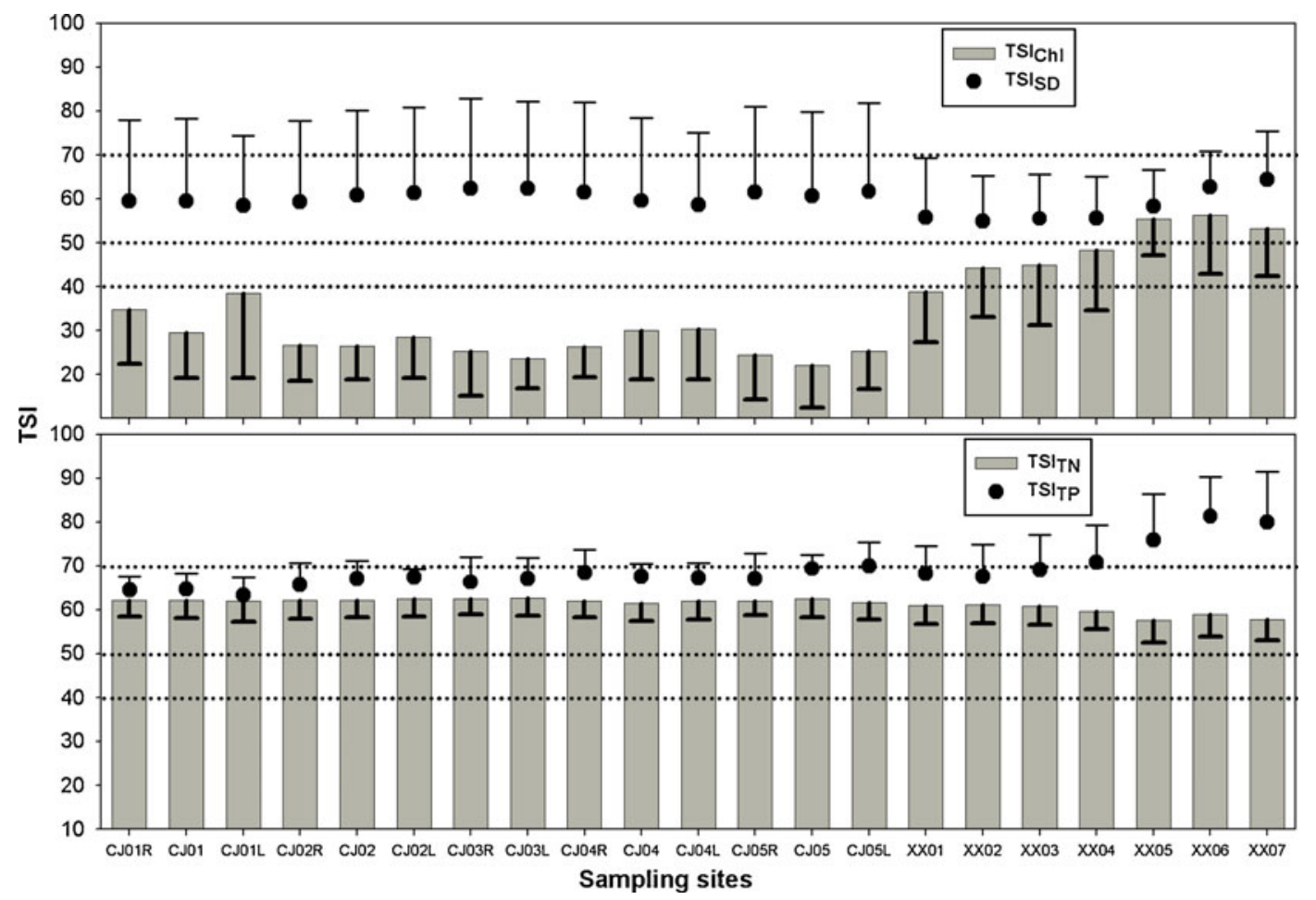

Fig. 2 Mean and standard deviation (bar) of trophic state indices for each sampling site. The dashed lines indicated the threshold value of hypertrophic (70), eutrophic (50), and mesotrophic (40) state 
spectrophotometer (Shimadzu UV-1601, Japan) according to the standard observation methods of aquatic ecosystem (Huang et al. 2000; Cai 2007). The concentrations of TN and TP were analyzed according to the user manual of Skalar on a segmented flow analyzer (Skalar SAN ${ }^{++}$, the Netherlands). The concentrations of NVSS were measured according to a standard operating procedure for suspended solids analysis (EPA 1993).

\subsection{Data Analysis}

Trophic state indices of the reservoir were calculated using the methods described by Carlson (1977) and Kratzer and Brezonik (1981). The equations are as follows:

$$
\begin{aligned}
& T S I_{S D}=60-14.42 \ln (S D) \\
& T S I_{T N}=54.45+14.43 \ln (T N) \\
& T S I_{T P}=14.42 \ln (T P)+4.15 \\
& T S I_{C H L}=9.81 \ln (C H L)+30.6
\end{aligned}
$$

The waters with TSI less than 40 are grouped into oligotrophic state, and the waters with TSI ranging from 40 to 50 are distinguished into mesotrophic state. If the TSI values range from 50 to 70 , the waters belong to eutrophic state. The value of TSI is higher than 70, suggesting hypertrophic state (Kratzer and Brezonik 1981).

The significant differences of $\mathrm{TSI}_{\mathrm{CHL}}$ from other trophic state indices $\left(\mathrm{TSI}_{\mathrm{SD}}, \mathrm{TSI}_{\mathrm{TN}}\right.$, and $\mathrm{TSI}_{\mathrm{TP}}$ ) were evaluated with paired-samples $t$ test. Intraclass correlation coefficient $(r)$ between the time series of two sampling sites was regarded as a measure of temporal coherence for trophic state indices and NVSS and was calculated as (modified from Rusak et al. 1999):

$r=\left(M S_{M}-M S_{E}\right) /\left(M S_{M}+M S_{E}\right)$

where $\mathrm{MS}_{\mathrm{M}}$ and $\mathrm{MS}_{\mathrm{E}}$ are the mean squares for the months and for the error of a two-way ANOVA (sites and months) without replication, respectively. When synchrony increases, $\mathrm{MS}_{\mathrm{E}}$ approaches zero, and $r$ approaches 1. When fluctuations are asynchronous, $\mathrm{MS}_{\mathrm{E}}$ will increase until it becomes higher than $\mathrm{MS}_{\mathrm{M}}$, and $r$ approaches -1 . The relationships between geographical distance, coherence for NVSS, and

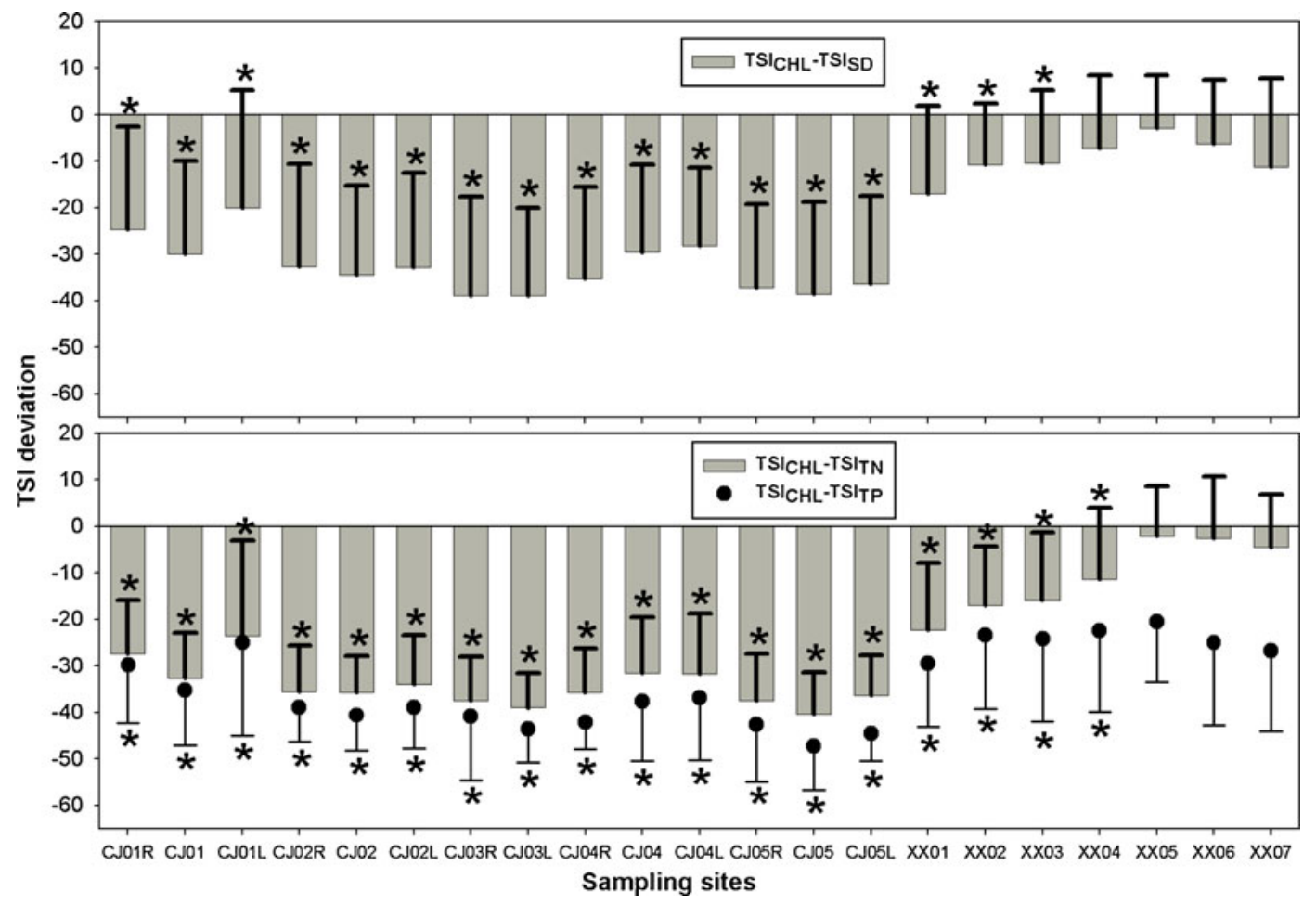

Fig. 3 Mean and standard deviation (bar) of TSI deviation for each sampling site. The star closed to bar represents that TSI $\mathrm{CHL}_{\mathrm{O}}$ of the sampling site was significantly $(p<0.05, t$ test) lower than the other indices 
asynchrony of trophic state indices were modeled by the regression analysis. Geographical distance between sites $\mathrm{i}$ and $\mathrm{j}$ was measured with Measure Tool based on Arc GIS 9.0 software. Statistical analysis including paired-samples $t$ test, intraclass correlation analysis, and regression analysis were run with SPSS 13.0.

\section{Results}

\subsection{Assessment of Trophic Status}

There were clear spatial and temporal variations in four trophic state indices across the selected study area of TGR (Fig. 2). The mean TSI $\mathrm{CHL}_{\text {of each site }}$ located in the mainstream were all less than 40 , suggesting an oligotrophic state, while the trophic state of Xiangxi Bay raised from oligotrophic state at the mouth to eutrophic state at the headwater. The seasonal variations of $\mathrm{TSI}_{\mathrm{CHL}}$ were observed in the mainstream and Xiangxi Bay of TGR, as showed by standard deviation (SD) of $\mathrm{TSI}_{\mathrm{CHL}}$ for each site (6.8 19.3). The mainstream and Xiangxi Bay of TGR were both characterized as eutrophic state, when the trophic state was based on mean $\mathrm{TSI}_{\mathrm{SD}}$ (54.9 64.4) or mean $\mathrm{TSI}_{\mathrm{TN}}$ of each site (57.6 62.4). The seasonal variation degree of TSI SD $_{\text {in }}$ the TGR mainstream $(15.9 \leq \mathrm{SD} \leq 21.9)$ was higher than that in Xiangxi Bay $(8.2 \leq \mathrm{SD} \leq 13.7)$, while the variation degree of $\mathrm{TSI}_{\mathrm{TN}}$ had no obvious difference between the TGR mainstream $(3.2 \leq \mathrm{SD} \leq 4.8)$ and Xiangxi Bay $(4.1 \leq \mathrm{SD} \leq 5.1)$. As showed by assessments based on mean $\mathrm{TSI}_{\mathrm{TP}}$, most sites of the mainstream were grouped into eutrophic state, while the trophic state of Xiangxi Bay changed from eutrophic state of the mouth to hypereutrophic state of the headwater. The seasonal variation degree of $\mathrm{TSI}_{\mathrm{TP}}$ in the TGR mainstream $(1.9 \leq \mathrm{SD} \leq 5.9)$ was lower than that in Xiangxi Bay $(6.3 \leq \mathrm{SD} \leq 11.6)$.
Fig. 4 Spatial pattern of temporal coherence $(r)$ for $\mathrm{TSI}_{\mathrm{CHL}}$ (upper triangle) and for $\mathrm{TSI}_{\mathrm{TP}}$ (lower triangle)

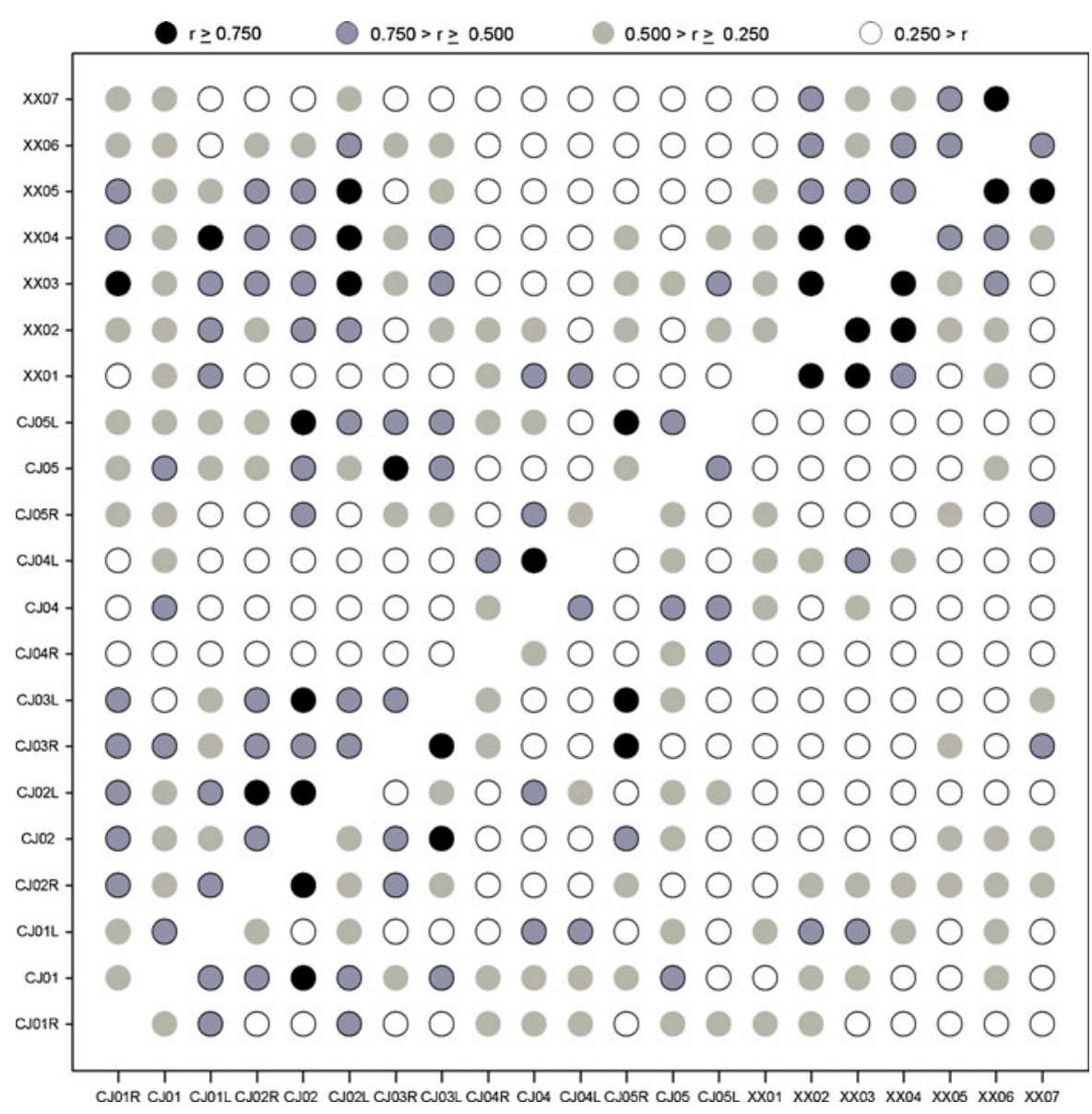


$\mathrm{TSI}_{\mathrm{CHL}}$ was significantly ( $p<0.05, t$ test) lower than $\mathrm{TSI}_{\mathrm{SD}}, \mathrm{TSI}_{\mathrm{TN}}$, and $\mathrm{TSI}_{\mathrm{TP}}$ at most sampling sites of selected area (Fig. 3). It showed that nonalgal turbidity dominated light attenuation $\left(\mathrm{TSI}_{\mathrm{CHL}}-\mathrm{TSI}_{\mathrm{SD}}<0\right)$, and nutrient inputs substantially exceeded the actual nutrient availability for algal production $\left(\mathrm{TSI}_{\mathrm{CHL}}-\mathrm{TSI}_{\mathrm{TN}}<0\right.$ and $\mathrm{TSI}_{\mathrm{CHL}}-\mathrm{TSI}_{\mathrm{TP}}<0$ ), following the concept of TSI differences (Carlson 1991). In other words, algal productivity in the mainstream of TGR and Xiangxi Bay except the upstream of the bay was always limited by nonalgal turbidity rather than nitrogen and phosphorus. Nonalgal turbidity had higher degree of limitation in the mainstream of TGR $(-39.9 \leq$ mean of $\left.\mathrm{TSI}_{\mathrm{CHL}}-\mathrm{TSI}_{\mathrm{SD}} \leq-20.1\right)$ than that in Xiangxi Bay $\left(-16.9 \leq\right.$ mean of $\left.\mathrm{TSI}_{\mathrm{CHL}}-\mathrm{TSI}_{\mathrm{SD}} \leq-3.0\right)$. The seasonal variations in the limitation degree of nonalgal turbidity for the TGR mainstream $(16.8 \leq \mathrm{SD} \leq 25.3)$ were often higher than that for Xiangxi Bay $(11.3 \leq \mathrm{SD} \leq 19.0)$. The mean of $\mathrm{TSI}_{\mathrm{CHL}}-\mathrm{TSI}_{\mathrm{TN}}$ and $\mathrm{TSI}_{\mathrm{CHL}}-\mathrm{TSI}_{\mathrm{TP}}$ at the mainstream ranged from -40.3 to -23.6 and from -47.2 to -24.9 , respectively, while those at Xiangxi Bay varied from -22.2 to -2.2 and from -29.6 to -20.5 , respectively. It indicted that the mainstream of TGR had higher degree of nutrient excess than Xiangxi Bay.

\subsection{Temporal Asynchrony for Trophic Status}

Among four trophic state indices, the lowest degrees of coherence were detected for $\mathrm{TSI}_{\mathrm{CHL}}$ and $\mathrm{TSI}_{\mathrm{TP}}$ (Fig. 4). The correlation coefficients of $\mathrm{TSI}_{\mathrm{CHL}}$ and $\mathrm{TSI}_{\mathrm{TP}}$ between all sampling sites ranged from -0.368 to 0.944 and from -0.493 to 0.940 , respectively, and the average coherences were both lower than 0.500 . Significant high levels of temporal coherence were observed between only $33.8 \%$ site-pairs for $\mathrm{TSI}_{\mathrm{CHL}}$ and between only $20.5 \%$ site-pairs for $\mathrm{TSI}_{\mathrm{TP}}$. The regional temporal asynchrony suggested that the intrinsic factors acting in each sites are the main responsible for temporal fluctuations of $\mathrm{TSI}_{\mathrm{CHL}}$ and $\mathrm{TSI}_{\mathrm{TP}}$. The highest levels of coherence were found for
Fig. 5 Spatial pattern of temporal coherence $(r)$ for $\mathrm{TSI}_{\mathrm{TN}}$ (upper triangle) and for $\mathrm{TSI}_{\mathrm{SD}}$ (lower triangle; the pane indicated the coherence between the mainstream and Xiangxi Bay of TGR)

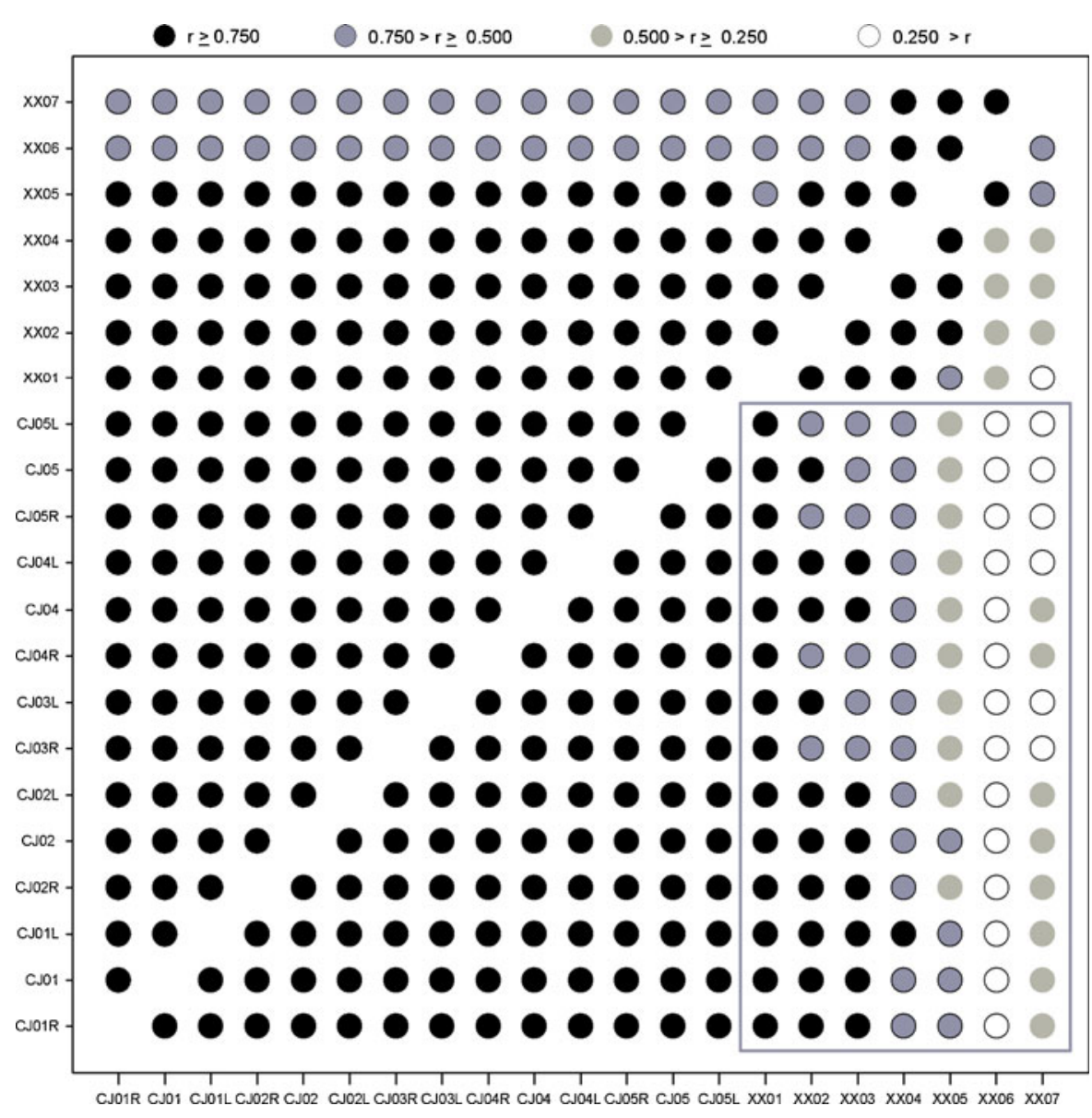

型 Springer 
$\mathrm{TSI}_{\mathrm{TN}}$ (Fig. 5). All $r$ values of $\mathrm{TSI}_{\mathrm{TN}}$ were statistically significant, and the correlation coefficients of TSI between all sampling sites ranged from 0.510 to 0.991 , with mean and median values of 0.895 and 0.927 , respectively. The regional synchrony indicated that temporal fluctuations of $\mathrm{TSI}_{\mathrm{TN}}$ were not regulated by local-scale factors. The coherence for TSI $_{\mathrm{SD}}$ was also relative high (mean $r=0.750$ ), but displayed substantial variation over spatial scale, ranging from 0.097 to 0.996 (Fig. 5). The lowest coherences for TSI $\mathrm{SD}_{\mathrm{SD}}$ were often observed between sites from the upstream of Xiangxi Bay and that from the downstream and the reservoir mainstream. It indicated that local processes of Xiangxi Bay played a role on the local asynchrony in temporal fluctuations of TSI SD. $_{\text {. }}$

Patterns of synchrony in seasonal dynamics were also analyzed for deviations from trophic state indices. The lowest degrees of coherence were detected for $\mathrm{TSI}_{\mathrm{CHL}}-\mathrm{TSI}_{\mathrm{TN}}$ and $\mathrm{TSI}_{\mathrm{CHL}}-\mathrm{TSI}_{\mathrm{TP}}$ (Fig. 6). The correlation coefficients for $\mathrm{TSI}_{\mathrm{CHL}}-\mathrm{TSI}_{\mathrm{TN}}$ and $\mathrm{TSI}_{\mathrm{CHL}}-\mathrm{TSI}_{\mathrm{TP}}$ ranged from -0.323 to 0.935 and from -0.406 to 0.929 , respectively, and the mean and median of coherences were lower than 0.500 . Significant high levels of temporal coherence were only found between $39.5 \%$ site-pairs for $\mathrm{TSI}_{\mathrm{CHL}}-\mathrm{TSI}_{\mathrm{TN}}$ and between $20.0 \%$ site-pairs for $\mathrm{TSI}_{\mathrm{CHL}}-\mathrm{TSI}_{\mathrm{TP}}$. Regional asynchrony suggested that the intrinsic factors of each site were the main responsible for temporal fluctuations of nutrient excess degree. The coherence for $\mathrm{TSI}_{\mathrm{CHL}}-\mathrm{TSI}_{\mathrm{SD}}$ was relatively high (mean $r=0.572$ ), but also showed substantial variation over spatial scale, ranging from -0.260 to 0.982 (Fig. 7). Low coherences for $\mathrm{TSI}_{\mathrm{CHL}}-\mathrm{TSI}_{\mathrm{SD}}$ were recorded between the mainstream and Xiangxi Bay or between sites within Xiangxi Bay, indicating that local processes of Xiangxi Bay were the main responsible for local asynchrony of nonalgal turbidity limitation levels.
Fig. 6 Spatial pattern of temporal coherence $(r)$ for $\mathrm{TSI}_{\mathrm{CHL}}-\mathrm{TSI}_{\mathrm{TN}}$ (upper triangle) and for $\mathrm{TSI}_{\mathrm{CHL}}-\mathrm{TSI}_{\mathrm{TP}}$ (lower triangle)

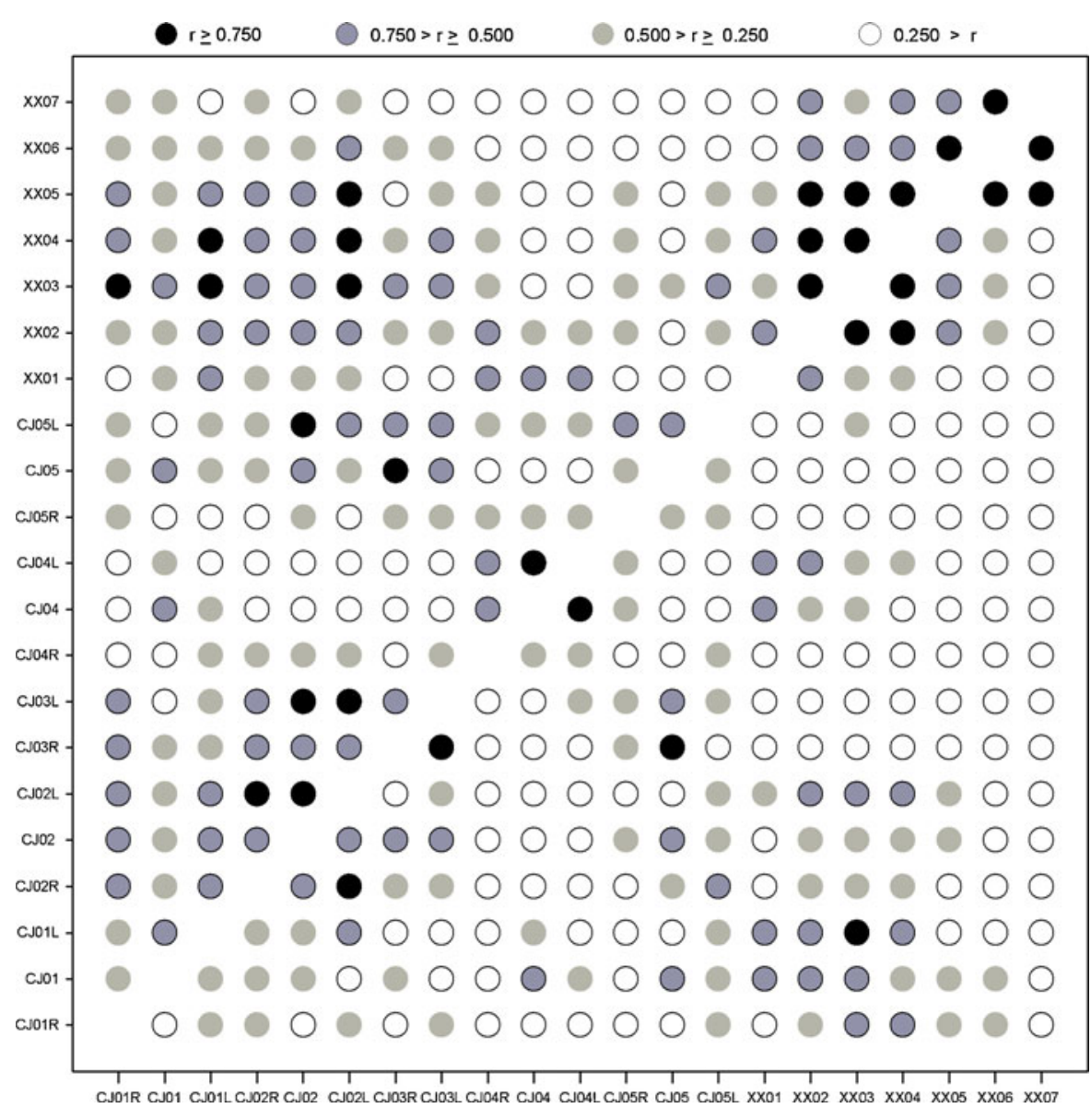


Fig. 7 Spatial pattern of temporal coherence $(r)$ for $\mathrm{TSI}_{\mathrm{CHL}}-\mathrm{TSI}_{\mathrm{SD}}$ (the pane indicated the coherence between the mainstream and Xiangxi Bay of TGR)

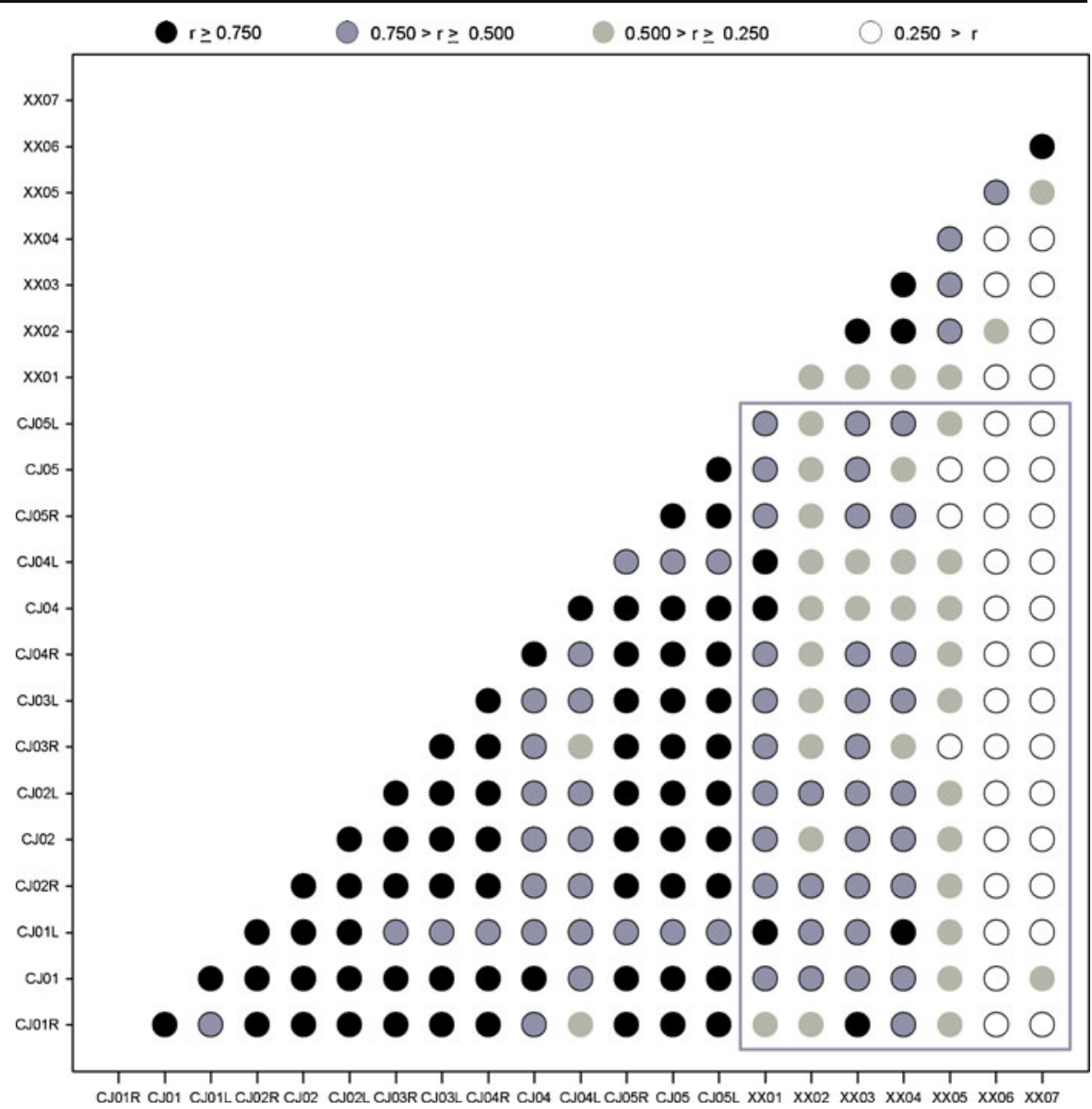

3.3 The Influencing Factors of Temporal Asynchrony

Geographical distance between pair sites greatly ranged from 0.3 to $50.2 \mathrm{~km}$, and was significantly related to temporal asynchrony for trophic state indices except $\mathrm{TSI}_{\mathrm{CHL}}$, but accounted for only $1.1 \sim 18.7 \%$ of the spatial variations in their coherences (Fig. 8). Temporal coherence for NVSS showed dramatic variations over spatial scales, ranging from -0.179 to 0.992 , and explained $85.2 \%$ of the spatial variation in coherences for $\mathrm{TSI}_{\mathrm{SD}}$, but accounted for only $2.8 \%$ and $4.3 \%$ of the variance in coherences for $\mathrm{TSI}_{\mathrm{CHL}}$ and $\mathrm{TSI}_{\mathrm{TP}}$, respectively. The coherences of TSI deviations between pair sites significantly decreased with geographical distance, but only $2.3 \sim 18.6 \%$ of the variance in coherences can be explained (Fig. 9). Coherence for NVSS was also a strong predictor of coherence for $\mathrm{TSI}_{\mathrm{CHL}}-\mathrm{TSI}_{\mathrm{SD}}$, while it was a weak predictor of coherence for $\mathrm{TSI}_{\mathrm{CHL}}-\mathrm{TSI}_{\mathrm{TN}}$ and $\mathrm{TSI}_{\mathrm{CHL}}-\mathrm{TSI}_{\mathrm{TP}}$. Those results of regression analysis indicated that local temporal asynchrony for TSI SD $_{\text {and nonalgal turbidity }}$ limitation levels were regulated by local dynamics of NVSS, rather than geographical distance.

\section{Discussions}

In the derivations of original TSI, Carlson's intention was to set up equations that would produce the same TSI value for a particular lake, regardless of whether chlorophyll $a$, phosphorus, or transparency was used to calculate the index of trophic state (Carlson 1977). The accuracy of the index values based on chlorophyll $a$, phosphorus, and transparency depends on the assumption that phosphorus was the main algal biomass-limiting factor, and that underwater light climate was dominated by phytoplankton rather than nonalgal turbidity. In reality, these assumptions are not easy to be demonstrated in many water bodies, and there are often obvious differences in the calculated trophic state (Matthews et al. 2002; An and Park 2003; Lee et al. 2010). In this case, Carlson (1991) suggested 

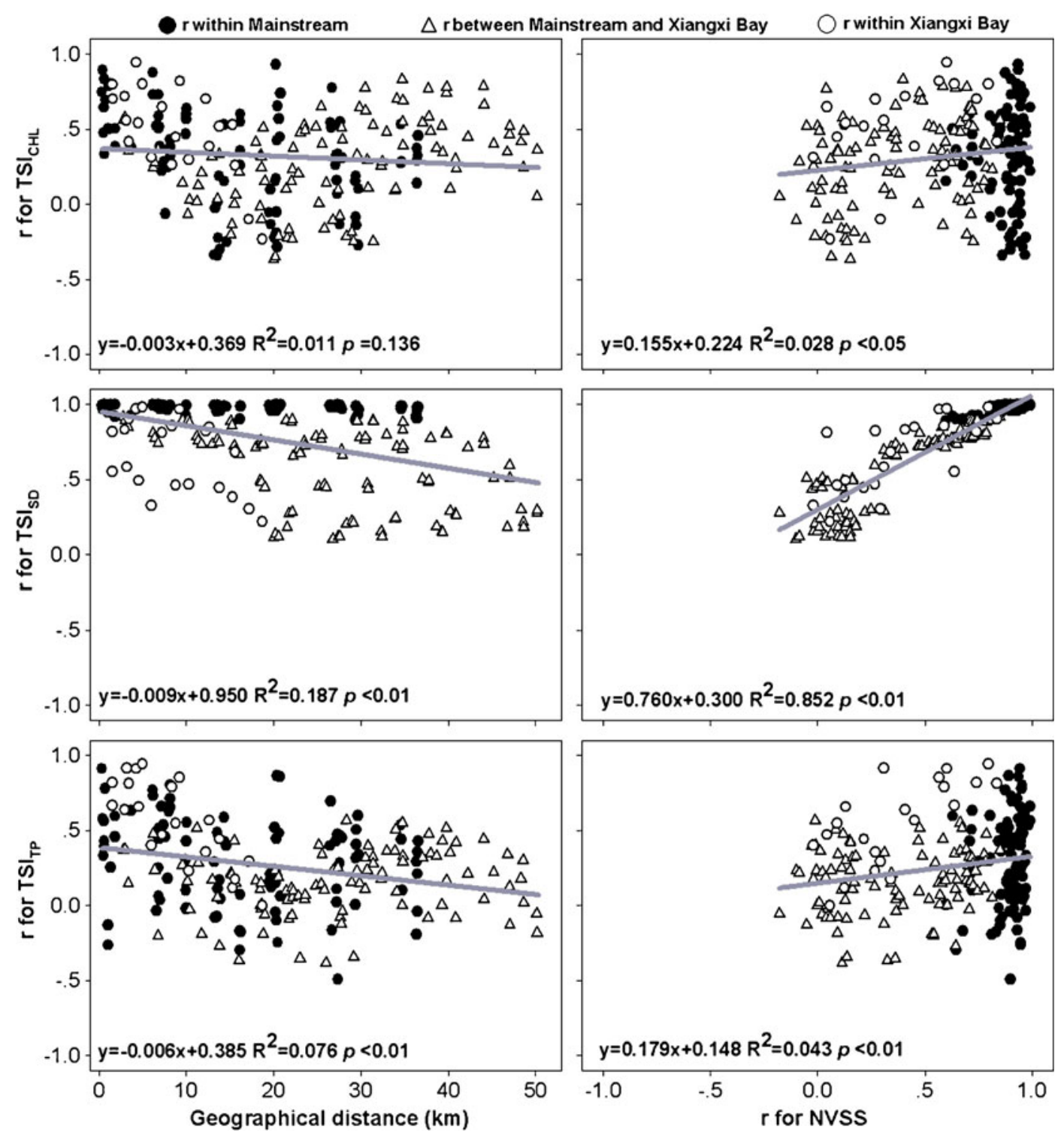

Fig. 8 Relationship between temporal asynchrony $(r)$ for trophic state $\left(\mathrm{TSI}_{\mathrm{CHL}}, \mathrm{TSI}_{\mathrm{SD}}, \mathrm{TSI} \mathrm{TP}_{\mathrm{TP}}\right)$, geographical distance $(\mathrm{km})$, and temporal coherence $(r)$ for NVSS

giving priority to biological parameters such as chlorophyll $a$ that represents visible symptoms of eutrophication, when classifying a lake's trophic status. Most researchers supported Carlson's idea that the trophic state index determined with chlorophyll $a$ would provide a better indication of lake trophic state than one determined with total phosphorus concentrations or transparency (e. g., Matthews et al. 2002; An and Park 2003; Lee et al. 2010). Following the common view, the results of this present study indicated that the mainstream of TGR would be placed in an oligotrophic category, and Xiangxi Bay changed from oligotrophic to eutrophic category between the mouth and headwater. The conclusions coincided with the frequent blooms observed in Xiangxi Bay, especially in its middle and upstream, instead of the mainstream of TGR (Ye et al. 2007; Wang et al. 2009; Xu et al. 2009a, 2010b), where no algal blooms have been reported until now.

Interestingly, Carlson (1991) expanded on the concept of TSI differences by providing a twodimensional graphical approach, in order to assess 

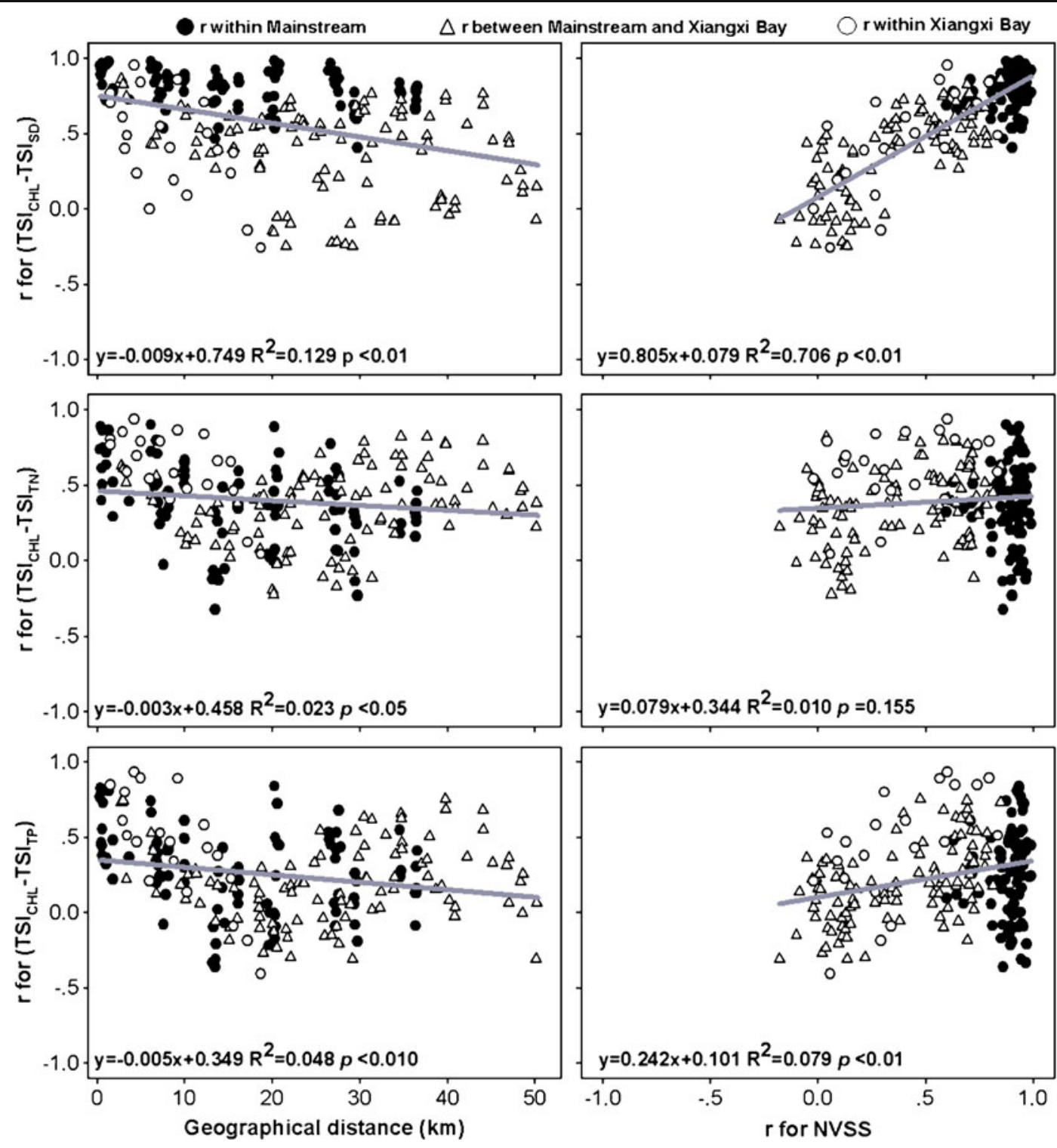

Fig. 9 Relationship between temporal asynchrony $(r)$ for TSI deviations, geographical distance (km), and temporal coherence $(r)$ for NVSS

the type and degree of limitation in lake ecosystems. When $\mathrm{TSI}_{\mathrm{CHL}}$ is equal to or greater than $\mathrm{TSI}_{\mathrm{SD}}$, one may infer that algae dominate light attenuation. When $\mathrm{TSI}_{\mathrm{CHL}}$ is substantially lower than $\mathrm{TSI}_{\mathrm{SD}}$, this provides evidence that something other than algae, perhaps color or nonalgal seston, is contributing to the light attenuation. When $\mathrm{TSI}_{\mathrm{CHL}}$ is equal to or greater than $\mathrm{TSI}_{\mathrm{TP}}$, phosphorus generally is limiting to algal growth. When $\mathrm{TSI}_{\mathrm{CHL}}$ is substantially lower than $\mathrm{TSI}_{\mathrm{TP}}$, this indicates that there is less algal material present than expected based on total phosphorus, and that some other factors may be limiting. In the same manner, the deviation between $\mathrm{TSI}_{\mathrm{CHL}}$ and $\mathrm{TSI}_{\mathrm{TN}}$ can be used to infer whether or not nitrogen limitation occurs. Those relationships have been extensively used by most related studies (e.g., Matthews et al. 2002; An and Park 2003; Lee et al. 2010). For instance, Matthews et al. (2002) employed the concept of TSI differences to assess the trophic state and nutrient limitation of Lake Whatcom (WA, USA). An and Park (2003) used deviations of the trophic state index to illustrate that factors other than 
phosphorus limited algal growth, and that nonalgal particles affected light attenuation in an Asian reservoir (Taechung Reservoir, Korean). In the present study, the trophic state index determined with chlorophyll $a$ presented lower values than those determined with total nitrogen, total phosphorus, and transparency, indicating that nonalgal turbidity rather than nitrogen and phosphorus limited phytoplankton growth.

Limnological studies have demonstrated that climate and hydrology are dominant factors regulating lake processes and functions (Lee et al. 2010). In Asian, monsoon rainfall accounts for $50-70 \%$ of total annual precipitation, and the importance of the monsoon in determining seasonal patterns of lake trophic status has been proved by many previous studies (An and Park 2003; Lee et al. 2010; Xu et al. 2010a). For instance, An and Park (2003) explored how the Asian monsoon influenced the trophic state of the Taechung Reservoir, Korea, and found that the disparity of the trophic state index during the intensive monsoon was a result from the short water retention time and the reduced light availability through dominance of NVSS. Lee et al. (2010) concluded that the trophic state of Imha Reservoir (Korean) was primarily controlled by the effect of phosphorus during the premonsoon and postmonsoon seasons, while the state was directly influenced by nonalgal light attenuation during intense monsoon. In the mainstream of TGR, the inflow discharges mostly concentrated from June to September (the flood season) under the regulation of summer monsoon, accounting for $61 \%$ of annual total (Huang et al. 2006), and the regulating role of the monsoon on trophic status has also been found by a recent research work (Xu et al. 2010a). Overall, those studies from the Asian reservoirs had considered the timing and intensity of the monsoon as the regional drivers of seasonal and year-to-year variations of trophic status, but there were a few prior investigations on temporal asynchrony of trophic status, and the role of local-scale regulators were often ignored by most researchers. According to the theory of Moran effect (Hudson and Cattadori 1999; Liebhold et al. 2004; Satake and Koizumi 2008), regional climatic factors could exert synchronous effects on trophic status in a single reservoir system. However, the present study did not show a clear case of the Moran effect, and found that local-scale regulators of Xiangxi Bay could disturb the responses of nonalgal turbidity limitation on regional scale factors. These findings were strongly supported by asynchronous dynamics of NVSS. Therefore, we argued that the results of trophic status obtained from a single environment (reservoir mainstream) cannot be extrapolated to other environments (tributary bay) in a way that would allow its use as a sentinel site.

Acknowledgments This work was funded by the Key Project of Knowledge Innovation Program of CAS (No. KZCX2-YW427), the National Natural Science Foundation of China (No. 40671197), and the State Key Laboratory FEBL Research Grant (2008FBZ02). We thank Ruiqiu Liu, Lin Ye, Fengqing Li, Shugui Duan, and Lan Wang for their assistance in the field and the lab. Special thanks are due to anonymous reviewers for their useful comments in improving this manuscript, and to Prof. Hongbin Liu and Dr. Emma Rocke for their help in correcting some mistakes in English style and grammar.

\section{References}

Ambrosetti, W., Barbanti, L., \& Sala, N. (2003). Residence time and physical processes in lakes. Journal of Limnology, 62, $1-15$.

An, K. G., \& Park, S. S. (2003). Influence of seasonal monsoon on the trophic state deviation in an Asian reservoir. Water, Air, \& Soil Pollution, 145, 267-287.

Cai, Q. (2007). Protocols for standard observation and measurement in aquatic ecosystems. Beijing: China Environmental Science Press. In Chinese.

Cai, Q., \& Hu, Z. (2006). Studies on eutrophication problem and control strategy in the Three Gorges Reservoir. Acta Hydrobiologica Sinica, 30, 7-11 (In Chinese with English Abstract).

Carlson, R. E. (1977). A trophic state index for lakes. Limnology and Oceanography, 22, 361-369.

Carlson, R. E. (1991). Expanding the trophic state concept to identify non-nutrient limited lakes and reservoirs. In Enhancing the states's lake management programs, pp. 59-71.

Carpenter, S. R. (2005). Eutrophication of aquatic ecosystems: bistability and soil phosphorus. Proceedings of the National Academy of Sciences, 102, 10002-10005.

Carpenter, S. R., Caraco, N. F., Correll, D. L., Howarth, R. W., Sharpley, A. N., \& Smith, V. H. (1998). Nonpoint pollution of surface waters with phosphorus and nitrogen. Ecological Applications, 8, 559-568.

Carpenter, S. R., Ludwig, D., \& Brock, W. A. (1999). Management of eutrophication for lakes subject to potentially irreversible change. Ecological Applications, 9, 751-771.

Conley, D. J., Paerl, H. W., Howarth, R. W., Boesch, D. F., Seitzinger, S. P., Havens, K. E., et al. (2009). Controlling eutrophication: nitrogen and phosphorus. Science, 323, 1014-1015.

Dillon, P. J., \& Rigler, F. H. (1974). The phosphoruschlorophyll relationship in lakes. Limnology and Oceanography, 19, 767-773. 
Environmental Protection Agency (U.S. EPA) (1993). Lake Michigan mass balance, methods compendium (volume 3): LMMB 065 (ESS Method 340.2). http://www.epa.gov/ greatlakes $/ \mathrm{lmmb} /$ methods/.

Fernández, C., Parodi, E. R., \& Cáceres, E. J. (2009). Limnological characteristics and trophic state of Paso de las Piedras Reservoir: an inland reservoir in Argentina. Lakes \& Reservoirs: Research and Management, 14, 85101.

Grenfell, B. T., Wilson, K., Finkenstadt, B. F., Coulson, T. N., Murray, S., Albon, S. D., et al. (1998). Noise and determinism in synchronized sheep dynamics. Nature, 394, 674-677.

Heisler, J. L., \& Knapp, A. K. (2008). Temporal coherence of aboveground net primary productivity in mesic grasslands. Ecography, 31, 408-416.

Hessen, D. O., \& Faafeng, B. A. (2006). Exrinsic and intrinsic controls of zooplankton diversity in lakes. Ecology, 87, 433-443.

Huang, X., Chen, W., \& Cai, Q. (2000). Survery, observation and analysis of lake ecology. Beijing: Standards Press of China. In Chinese.

Huang, Z., Li, Y., Chen, Y., Li, J., Xing, Z., Ye, M., et al. (2006). Water quality prediction and water environmental carrying capacity calculation for Three Gorges Reservoir. Beijing: China Water Power Press. In Chinese with English Abstract.

Hudson, P. J., \& Cattadori, I. M. (1999). The Moran effect: a cause of population synchrony. Trends in Ecology \& Evolution, 14, 1-2.

Kent, A. D., Yannarell, A. C., Rusak, J. A., Triplett, E. W., \& Mcmahon, K. D. (2007). Synchrony in aquatic microbial community dynamics. The International Society of Microbial Ecology Journal, 1, 38-47.

Knowlton, M. F., \& Jones, J. R. (2007). Temporal coherence of water quality variables in a suite of Missouri reservoirs. Lake and Reservoir Management, 23, 49-58.

Kratzer, C. R., \& Brezonik, P. L. (1981). A carlson-type trophic state index for nitrogen in florida lakes. Water Resources Bulletin, 17, 713-715.

Lansac-Tôha, F. A., Bini, L. M., Velho, L. F. M., Bonecker, C. C., Takahashi, E. M., \& Vieira, L. C. G. (2008). Temporal coherence of zooplankton abundance in a tropical reservoir. Hydrobiologia, 614, 387-399.

Lee, J., Kim, J. M., Kim, D. S., Hwang, S. J., \& An, K. G. (2010). Nutrients and chlorophyll $a$ dynamics in a temperate reservoir influenced by Asian monsoon along with in situ nutrient enrichment bioassays. Limnology, 11, 49-62.

Lichstein, J. W., Simons, T. R., Shriner, S. A., \& Franzreb, K. E. (2002). Spatial autocorrelation and autoregressive models in ecology. Ecological Monographs, 72, 445-463.

Liebhold, A., Koenig, W. D., \& Bjørnstad, O. N. (2004). Spatial synchrony in population dynamics. Annual Review of Ecology, Evolution, and Systematics, 35, 467-490.

Magnuson, J. J., Benson, B. J., \& Kratz, T. K. (1990). Temporal coherence in the limnology of a suite of lakes in Wisconsin, U.S.A. Freshwater Biology, 23, 145-159.

Matthews, R., Hilles, M., \& Pelletier, G. (2002). Determining trophic state in Lake Whatcom, Washington (USA), a soft water lake exhibiting seasonal nitrogen limitation. Hydrobiologia, 468, 107-121.
Moran, P. A. P. (1953). The statistical analysis of the canadian lynx cycle 2: synchronization and meteorology. Australian Journal of Zoology, 1, 291-298.

Nyenje, P. M., Foppen, J. W., Uhlenbrook, S., Kulabako, R., \& Muwanga, A. (2010). Eutrophication and nutrient release in urban areas of sub-Saharan Africa-a review. Science of the Total Environment, 408, 447-455.

Patoine, A., \& Leavitt, P. R. (2006). Century-long synchrony of fossil algae in a chain of Canadian prairie lakes. Ecology, $87,1710-1721$.

Poor, N. (2010). Effect of lake management efforts on the trophic state of a subtropical shallow lake in Lakeland, Florida, USA. Water, Air, \& Soil Pollution, 207, 333-347.

Pöyry, J., Paukkunen, J., Heliölä, J., \& Kuussaari, M. (2009). Relative contributions of local and regional factors to species richness and total density of butterflies and moths in semi-natural grasslands. Oecologia, 160, 577-587.

Rusak, J. A., Yan, N. D., Somers, K. M., \& Mcqueen, D. J. (1999). The temporal coherence of zooplankton population abundances in neighboring north-temperate lakes. American Naturalist, 153, 46-58.

Rusak, J. A., Yan, N. D., \& Somers, K. M. (2008). Regional climatic drivers of synchronous zooplankton dynamics in north-temperate lakes. Canadian Journal of Fisheries and Aquatic Sciences, 65, 878-889.

Satake, A., \& Koizumi, I. (2008). Population synchrony in ecological systems. Population Ecology, 50, 325-327.

Schindler, D. W. (2006). Recent advances in the understanding and management of eutrophication. Limnology and Oceanography, 51, 356-363.

Shao, M., Xie, Z., Han, X., Cao, M., \& Cai, Q. (2008a). Macroinvertebrate community structure in Three-Gorges Reservoir, China. International Review of Hydrobiology, 93, 175-187.

Shao, M., He, L., Han, X., \& Xie, Z. (2008b). Seasonal patterns of sedimentation and their associations with benthic communities in Xiangxi bay of the Three Gorges Reservoir, china. Journal of Freshwater Ecology, 23, 151-160.

Shurin, J., Cottenie, K., \& Hillebrand, H. (2009). Spatial autocorrelation and dispersal limitation in freshwater organisms. Oecologia, 159, 151-159.

Smith, V. (2003). Eutrophication of freshwater and coastal marine ecosystems: a global problem. Environmental Science and Pollution Research, 10, 126-139.

Smith, V. H., Joye, S. B., \& Howarth, R. W. (2006). Eutrophication of freshwater and marine ecosystems. Limnology and Oceanography, 51, 351-355.

Soballe, D. M., \& Kimmel, B. L. (1987). A large-scale comparison of factors influencing phytoplankton abundance in rivers, lakes, and impoundments. Ecology, 68, 1943-1954.

Straškraba, M., \& Tundisi, J. G. (1999). Guidelines of lake management (Volume 9): Reservoir water quality management. Japan: International Lake Environment Committee.

Wang, L., Cai, Q., Zhang, M., Lu, T., Xu, Y., \& Kong, L. (2009). Spatiotemporal dynamics and related affecting factors of summer algal blooms in Xiangxi Bay of Three Gorges Reservoir. Chinese Journal of Applied Ecology, 20, 1940-1946.

Wetzel, R. G. (2001). Limnology, lake and river ecosystems (3rd ed.). London: Academic. 
Xu, Y., Wang, L., Cai, Q., \& Ye, L. (2009a). Temporal coherence of chlorophyll $a$ during a spring phytoplankton bloom in Xiangxi Bay of Three-Gorges Reservoir, China. International Review of Hydrobiology, 94, 656-672.

Xu, Y., Cai, Q., Shao, M., Han, X., \& Cao, M. (2009b). Seasonal dynamics of suspended solids in a giant subtropical reservoir (China) in relation to internal processes and hydrological features. Quaternary International, 208, 138-144.

Xu, Y., Cai, Q., Han, X., Shao, M., \& Liu, R. (2010a). Factors regulating trophic status in a large subtropical reservoir, China. Environmental Monitoring and Assessment, 169, 237-248.
Xu, Y., Cai, Q., Wang, L., Kong, L., \& Li, D. (2010b). Diel vertical migration of Peridiniopsis niei, Liu et al., a new species of dinoflagellates in an eutrophic Bay of Three-Gorge Reservoir, China. Aquatic Ecology, 44, 387-395.

Ye, L., Han, X., Xu, Y., \& Cai, Q. (2007). Spatial analysis for spring bloom and nutrient limitation in Xiangxi Bay of Three Gorges Reservoir. Environmental Monitoring and Assessment, 127, 135-147.

Zheng, B., Zhang, Y., Fu, G., \& Liu, H. (2006). On the assessment standards for nutrition status in the Three Gorge Reservoir. Acta Scientiae Circumstantiae, 26, 1022-1030 (In Chinese with English Abstract). 